Chongdoo Park M ${ }^{*}$
Jae-H yon Bahk M,$\dagger$
Won-Sik Ahn M D, $†$
Sang-H wan Do MD,
Kook-H yun Lee MD $\dagger$

\section{The laryngeal mask airway in infants and children}

de l'épiglotte- vision du larynx obstruée par l'épiglotte : $<50 \% ; 4$, épiglotte repliée vers le bas et vision de sa surface antérieure- vision du larynx obstruée par l'épiglotte : > $50 \% ; 5$, épiglotte repliée vers le bas et vision indirecte du larynx. On a mesuré les volumes courants inspiratoire et expiratoire (VT) et la pression des voies aériennes avec un pneumotachomètre et on a calculé le pourcentage de fuite (PF). Dans 79 cas, le ML a été utilisé pour maintenir la perméabilité des voies aériennes tout au long de l'intervention.

R ésultats: La mise en place réussie du ML a été réalisée dans $98 \%$ des cas : trois échecs étaient liés à une insufflation gastrique. Les grades [médiane (intervalle)] de FB ont été, pour les $M L 1,1,5$, 2 et 2,5 de 3(1-5), 3(1-5), 1(1-5) et 1(1-3) respectivement. Dans le cas des $M L$ plus petits, le ballonnet couvrait fréquemment l'épiglotte $(P<$ $0,001)$. Le PF du ML 1 a été plus élevé que ceux des $M L 1,5$ et 2,5 $(P<0,05)$; le $P F$ du $M L 2$ a été plus élevé que celui du $M L 2,5$ ( $P$ $<0,05)$. Parmi les 79 patients, plus la taille du ML était grande, moins nombreux étaient ceux qui présentaient des complications $(P<$ 0,05).

Condusion : L'utilisation du ML chez les jeunes enfants entraîne davantage d'obstruction des voies aériennes, des pressions ventilatoires plus élevées, une fuite inspiratoire plus grande et plus de complications que chez les enfants plus âgés.

A LTHOUGH the laryngeal mask airway (LMA) has been recommended in situations, where positive pressure ventilation (PPV) is necessary, there are few investigations of its utility in this situation. ${ }^{1-8}$ We were unable to find any studies about LM A insertion, its positioning, and/ or its effect on controlled ventilation in paralyzed pediatric patients. No LMA study has been performed with the recommended sizes in large numbers of infants and young children.

Several LMA studies of infants have been reported. ${ }^{7-12}$ In some, ${ }^{7,9,10}$ only a few infants weighing $>5$ $\mathrm{kg}$ were included. Size \# 1 LMA (LMA 1) was used for 33 infants, but the mean weight was $5.6 \mathrm{~kg} .{ }^{11} \mathrm{In}$ a

From the D epartment of Anesthesiology, N ational Cancer Center,* Koyang, Kyunggi-D o, Korea and the D epartment of Anesthesiology and Clincal Research Institute, † Seoul N ational U niversity H ospital, Seoul, Korea.

Work undertaken in Seoul $\mathrm{N}$ ational U niversity $\mathrm{H}$ ospital supported from departmental sources.

A ddress correspondence to: D r. Jae-H yon Bahk, D epartment of Anesthesiology, Seoul $\mathrm{N}$ ational U niversity College of M edicine, \#28

Yongon-D ong, Chongno-Gu, Seoul 110-744, Korea. Phone: 82-2-760-2818; Fax: 82-2-747-5639; E-mail: bahkjh@plaza.snu.ac.kr

A ccepted for publication D ecember 20, 2000. 
study of 50 infants, whose weight range was 3.8-10.0 $\mathrm{kg}$, only the LMA 1 was used. ${ }^{12}$ These previous studies were performed in spontaneously breathing patients. Since size \# 1.5 LM A (LMA 1.5), the recommended body weight of which is $5-10 \mathrm{~kg}$, became available recently, a study of LMA $1,1.5$ or size \# 2 LMA (LMA 2) was warranted.

There were three objectives for this study: first, to assess the position of the LMA when it is inserted in paralyzed pediatric patients; second, to evaluate the competence of PPV when the LMA is used to maintain airway patency in paralyzed pediatric patients; third, to compare the efficacy of the various LMA sizes using the above measures.

\section{$M$ aterials and methods}

After institutional ethics board approval and informed parental consent, pediatric patients ( $n=158 ; 110$ male, 48 female) weighing $<30 \mathrm{~kg}$ and of ASA physical status 1 or 2 were studied during elective surgical procedures. Patients with lung disease, upper airway abnormality or infection, or undergoing intra-abdominal surgery were excluded. In the operating room, anesthesia was induced with thiopental iv or via a face mask with $\mathrm{O}_{2}-\mathrm{N}_{2} \mathrm{O}$ - halothane and, if not already in place, an intravenous line was established. Three minutes after $0.15 \mathrm{mg} \cdot \mathrm{kg}^{-1}$ vecuronium iv, neuromuscular blockade was assessed with train-of-four stimulation. Anesthesia was maintained with $\mathrm{O}_{2}$-air-isoflurane, and paralysis was maintained with repeated administration of vecuronium iv.

An LMA 1 was used for infants $<5 \mathrm{~kg}$; an LMA 1.5 for 5 - $10 \mathrm{~kg}$; an LM A 2 for $10-20 \mathrm{~kg}$; and a size \# 2.5 LMA (LMA 2.5) for 20 - $30 \mathrm{~kg}$. An experienced investigator inserted all the LMAs following the manufacturer's recommendations. ${ }^{13}$ The leak pressure was measured by auscultation after the cuff was inflated with air to $80 \%$ of the maximum recommended inflation volume, and again after injecting an additional 10\% If there was a decrease in leak pressure after injecting an additional $10 \%, 80 \%$ of the maximum inflation volume was used unless, another $10 \%$ more would achieve $100 \%$ of the maximum volume. If leak pressure at $100 \%$ was lower than that at $90 \%, 90 \%$ was selected. 0 therwise, $100 \%$ of the maximum recommended inflation volume was used. $\mathrm{N}$ amely, the inflation volume at a higher leak pressure was selected. All parameters including tidal volume $\left(\mathrm{V}_{\mathrm{T}}\right)$ and peak inspiratory pressure (PIP) were measured after the end-tidal $\mathrm{CO}_{2}$ partial pressure $\left(\mathrm{P}_{\mathrm{ET}} \mathrm{CO}_{2}\right)$ was stable. The $L M A$ was connected to a volume ventilator ( $D$ ameca $A / S$, Copenhagen, D enmark) incorporated into the anesthesia machine, and PPV with inspiratory to expiratory ratio of 1:2 was instituted. The $V_{T}$ was set at about 10 $\mathrm{ml} \cdot \mathrm{kg}^{-1}$ and, depending on age, a respiratory rate of 20$40 \cdot \mathrm{min}^{-1}$ was chosen to maintain the $\mathrm{P}_{\mathrm{ET}} \mathrm{CO}_{2}$ at 30 $35 \mathrm{mmH}$ g. On a randomized basis, using odd or even hospital numbers, patients were assigned to LMA use throughout surgery or to endotracheal intubation. For infants $<10 \mathrm{~kg}$, the LM A was connected to the ventilator via an infant circle system (Aika Medical Corp., Tokyo, Japan). A CP-100 neonatal pulmonary monitor (Bicore M onitoring Systems, Irvine, California, U SA) with a disposable VarFlex ${ }^{\circledR}$ flow transducer was used to measure inspiratory and expiratory $\mathrm{V}_{T}$. For children $>$ $10 \mathrm{~kg}$, a CP-100 adult pulmonary monitor (Bicore M onitoring Systems, I rvine, Calif.) was used. The CP100 pulmonary monitor is a pneumo-tachometer, the flow transducer of which is inserted between the patient's L M A adapter and Y-connector. M easurements were taken over 10 breaths. The PIP was recorded from the pulmonary monitor reading. The fraction of leakage $\left(F_{L}\right)(\%)$ was defined as:

$$
\begin{aligned}
F_{L}= & {\left[\left(\text { inspiratory } V_{T} \text { - expiratory } V_{T}\right) /\right.} \\
& \text { inspiratory } \left.V_{T}\right] \times 100 \text {. }
\end{aligned}
$$

The position and effectiveness of the LMA were assessed using the folllowing techniques and, once the position was clinically acceptable, no further adjustment to the LMA position was made. First, manual ventilation was possible with regular $\mathrm{ETCO}_{2}$ display without gastric distention; second, bilateral breath sounds as heard by auscultation over axillae. If not acceptable, the LM A was removed and re-inserted. It was regarded as a failure if the positioning of $L M A$ was not clinically acceptable after three attempts. The lar$y n x$ was inspected through the self-sealing diaphragm of an elbow connector, using a fibreoptic bronchoscope (FOB; Olympus LF-P, Olympus O ptical C O., Tokyo, Japan) located just proximal to the aperture bars, while an assistant prevented the L M A from moving. The FOB findings were defined as Grade 1 , larynx only seen; G rade 2, larynx and epiglottis posterior surface seen; Grade 3, larynx, and epiglottis tip or anterior surface seen-visual obstruction of epiglottis to larynx: <50\%; Grade 4, epiglottis down-folded, and its anterior surface seen-visual obstruction of epiglottis to larynx: > 50\%; G rade 5, epiglottis downfolded and larynx cannot be seen directly.

By placing a stethoscope on the stomach, gastroesophageal insufflation at $30 \mathrm{cmH}_{2} \mathrm{O}$ airway pressure was qualitatively assessed by an independent observer. The observer measured the leak pressure by using a stethoscope placed on the neck, while the lungs were manually inflated at $5 \mathrm{cmH}_{2} \mathrm{O}$ intervals until an air leak was audible. 
TABLE I PIP, $V_{T}, F_{L}$ and leak pressure at each LMA size

\begin{tabular}{|c|c|c|c|c|c|c|c|}
\hline & $\begin{array}{l}\text { A ge } \\
\text { (months) }\end{array}$ & $\begin{array}{l}\text { Body } \\
\text { Weight }(\mathrm{kg})\end{array}$ & $\begin{array}{l}\mathrm{PIP} \\
\left(\mathrm{cmH}_{2} \mathrm{O}\right)\end{array}$ & $\begin{array}{l}\text { Inspiratory } \\
\mathrm{V}_{\mathrm{T}}(\mathrm{ml})\end{array}$ & $\begin{array}{l}\text { Expiratory } \\
V_{T}(\mathrm{ml})\end{array}$ & $F_{L}(\%)$ & $\begin{array}{l}\text { Leak Pressure } \\
\left(\mathrm{cmH}_{2} \mathrm{O}\right)\end{array}$ \\
\hline $\begin{array}{l}\text { LMA \# } 1 \\
(n=25)\end{array}$ & $1.6 \pm 1.2$ & $4.2 \pm 1.0$ & $18 \pm 3 *$ & $32 \pm 5$ & $28 \pm 5$ & $12.0 \pm 3.4$ & $21 \pm 10$ \\
\hline $\begin{array}{l}\text { LM A \# } 1.5 \\
(n=41)\end{array}$ & $7.3 \pm 5.6$ & $7.5 \pm 1.5$ & $18 \pm 3 \dagger$ & $74 \pm 29$ & $69 \pm 28$ & $7.8 \pm 3.6 \ddagger$ & $21 \pm 8$ \\
\hline $\begin{array}{l}\text { LM A \# } 2 \\
(n=68)\end{array}$ & $39 \pm 20$ & $15 \pm 3$ & $16 \pm 3$ & $198 \pm 41$ & $174 \pm 31$ & $11.4 \pm 7.6$ & $21 \pm 8$ \\
\hline $\begin{array}{l}\text { LM A \# } 2.5 \\
(n=21)\end{array}$ & $81 \pm 17$ & $24 \pm 3$ & $14 \pm 3$ & $283 \pm 36$ & $263 \pm 36$ & $7.2 \pm 2.4 \ddagger \S$ & $21 \pm 11$ \\
\hline
\end{tabular}

$\mathrm{LMA}=$ laryngeal mask airway, $\mathrm{PIP}=$ peak inspiratory pressure, $\mathrm{V}_{\mathrm{T}}=$ tidal volume, $\mathrm{F}_{\mathrm{L}}=$ fraction of leakage.

$D$ ata are mean $\pm S D$.

$* \mathrm{P}<.05$, compared with PIP for LM A 2.5; †P <.05, compared with PIP for LMA $2 \& 2.5$.

$\ddagger P<.05$, compared with $F_{L}$ for $L M A 1 ; \S P<.05$, compared with $F_{L}$ for $L M A 2$.

$F_{L}(\%)=\left[\left(\right.\right.$ inspiratory $V_{T}$ - expiratory $\left.V_{T}\right) /$ inspiratory $\left.V_{T}\right] \times 100$.

If $\mathrm{P}_{\mathrm{ET}} \mathrm{CO}_{2}$ increased, but was still $<45 \mathrm{mmH} \mathrm{g}$, head flexion, ${ }^{14}$ head extension or mandibular elevation was tried. If all procedures failed, the cuff volume was changed. When $\mathrm{P}_{\mathrm{ET}} \mathrm{CO}_{2}$ increased to $>45 \mathrm{mmH}$ g, the LMA was removed and changed to an endotracheal tube. At the end of surgery, FOB was performed to recheck the position of the $L M A$.

\section{Statistical analysis}

The PIPs were compared with Kruskal-Wallis test. A nalysis of variance (ANOVA) with D uncan's test for multiple comparisons was used to compare the $F_{L}$ of each LM A size. FO B findings of each LM A size were compared with ridit test. The duration of PPV was compared with ANOVA. While maintaining PPV through $L M A$, the number of patients with problems among the groups of each LMA size was compared using Fisher's exact test. A P-value $<.05$ was considered significant.

\section{Results}

Successful LMA placement was achieved at the first attempt in $97 \%(153 / 158)$ of cases. Two of the remaining cases were successful at the second attempt. There were three failures due to gastric insufflation: one each in LMA 1, 1.5 and 2. Continuous leakage was found in seven cases: two in LMA 1 , three in LMA 1.5 and two in LMA 2. Cuff volumes used were $80 \%(16 / 155), 90 \%(16 / 155)$ or $100 \%(123 / 155)$ of the maximum recommended volumes.

The PIP varied with the LMA size $(P<.001)$ (Table I): PIP of smaller LM As was higher than that of larger LMAs. The $F_{L}$ of LMA \#1, 1.5, 2, and 2.5 (mean \pm SD) was respectively $12.0 \pm 3.4,7.8 \pm 3.6$, $11.4 \pm 7.6$, and $7.2 \pm 2.4 ; F_{L}$ of LMA 1 was higher
TABLE II LMA size and fibreoptic bronchoscopic finding when LMA was inserted after paralysis

\begin{tabular}{llllll}
\hline & \multicolumn{5}{c}{ Bronchoscopic Grade } \\
& 1 & 2 & 3 & 4 & 5 \\
\hline LM A \#1 $(n=25)$ & 5 & 2 & $11^{*}$ & 5 & 2 \\
LM A\#1.5 $(n=41)$ & 7 & 1 & $16^{*}$ & 9 & 8 \\
LM A \#2 $(n=68)$ & $35^{*}$ & 13 & 10 & 8 & 2 \\
LM A \#2.5 $(n=21)$ & $15^{*}$ & 5 & 1 & 0 & 0 \\
\hline
\end{tabular}

LM A = laryngeal mask airway

Fibreoptic bronchoscopic finding was defined as Grade 1, larynx only seen; Grade 2, larynx and epiglottis posterior surface seen;

Grade 3, larynx, and epiglottis tip or anterior surface seen-visual obstruction of epiglottis to larynx: less than $50 \%$; Grade 4, epiglottis down-folded, and its anterior surface seen-visual obstruction of epiglottis to larynx: more than $50 \%$ Grade 5, epiglottis down-folded and larynx cannot be seen directly. $\mathrm{P}<.001$, ridit test. $*$ data of the median.

than those of LMA 1.5 and LMA $2.5(P<.05)$, and $F_{L}$ of LMA 2 was higher than that of LMA 2.5 (P< .05 ) (Table I). In smaller LMAs, the cuff more frequently enclosed the epiglottis than in larger LM As ( $P$ $<.001$ ) (Table II).

Among 79 patients in when an LMA was used for airway maintenance throughout the operation, there were nine cases of continuous $\mathrm{P}_{E T} \mathrm{CO}_{2}$ increase ( $\mathrm{T}$ able III); the FOB grade was 3 in six patients, 4 in two and 5 in one. Their FOB findings at the end of surgery did not change when compared with the initial findings. When we attempted to solve the problem, the mandibular elevation worked well in two of the nine only while elevating the mandible with both hands. Because of high $\mathrm{P}_{E T} \mathrm{CO}_{2}$, the LM A was removed in two of the nine (LMA 1.5 and 2 each). O ne of the nine 
TABLE III Duration of PPV through LMA and incidence of complications while maintaining PPV through LM A

\begin{tabular}{|c|c|c|c|c|c|}
\hline & $\begin{array}{l}\text { Duration of PPV } \\
\text { (min) }\end{array}$ & $\begin{array}{l}\text { Laryngo- } \\
\text { spasm }\end{array}$ & $\begin{array}{l}\text { Complications } \\
\text { Vomiting }\end{array}$ & $\begin{array}{l}\mathrm{P}_{\mathrm{ET}} \mathrm{CO}_{2} \\
\text { increase }\end{array}$ & $\begin{array}{l}\mathrm{N} \text { umber of patients } \\
\text { with morethan one } \\
\text { complication* }\end{array}$ \\
\hline Total $(n=79)$ & $45 \pm 23(15-165)$ & 3 & 1 & 9 & $12(15 \%)$ \\
\hline LM A \#1 (n=10) & $53 \pm 14(40-80)$ & 0 & 0 & 3 & $3(30 \%)$ \\
\hline LMA \#1.5 (n=27) & $44+14(15-80)$ & 2 & 0 & 5 & $7(26 \%)$ \\
\hline LMA \#2 $(n=31)$ & $47 \pm 31(20-165)$ & 1 & 1 & 1 & $2(7 \%)$ \\
\hline LM A \#2.5 $(n=11)$ & $42+11(30-60)$ & 0 & 0 & 0 & $0(0 \%)$ \\
\hline
\end{tabular}

Values are mean \pm SD (range).

Duration of PPV was not different $(P=.91)$.

*The number of patients, who had more than one complication, was different depending on the LM A size $(P<.05)$

PPV = positive pressure ventilation, LM A = laryngeal mask airway

vomited during emergence, while the LMA was still in place (Table III). There was no evidence of aspiration. The other LMAs were removed after reflexes had returned. There was no case of hypoxia, $\mathrm{SpO}_{2}<95 \%$ The number of patients experiencing complications decreased as LM A size increased $(P<.05)$ (T able III).

\section{Discussion}

In this study using appropriately sized LM As in infants and children, older children had better LM A position and less leakage around the LMA during PPV. Also, older children had fewer complications while maintaining PPV through LMA. The LMA can be used safely for PPV during surgery of short duration in older children but cannot be recommended for infants.

Because of individual variation in the size of the larynx, the LM A sometimes encloses the epiglottis, even when the tip of its cuff correctly occupies the hypopharynx. ${ }^{15}$ In the majority of correctly placed LM As in children, the epiglottis lies within the confines of the mask. ${ }^{9,11,12} \mathrm{H}$ owever, optimal position of the LMA (FOB grade 1) was achieved in a comparatively large proportion of infants $\left(29 \%^{11}\right.$ or $\left.44 \%^{12}\right)$, where smaller-size LMAs than recommended were used. In our study, the FOB grade was higher in neonates and infants, so that a satisfactory position was more difficult to achieve in those age groups as suggested by Wilson. ${ }^{16}$ In children who weighed $>10$ $\mathrm{kg}$, the FOB finding was improved. This was comparable to our clinical impression that LMA $>2$ is easier to use than smaller LMAs. This may be partly because the LMA was designed after cadaveric examination of the adult larynx, and the small LM A is a scaled-down version of the adult LMA. ${ }^{17}$ Although the anatomy regarding the LMA is reported to be comparable in infants, ${ }^{18}$ the anatomy of the larynx of infants differs from that of children. Thus, it might be more difficult to achieve a good position with an infantile size L M A than with a pediatric size.

Even though the airway diameter of the LMA is larger than that of a comparable endotracheal tube and the LMA does not occupy the narrowest portion of the upper airway (the cricoid cartilage), PIP through the small LMA was not particularly low. Incorporation of the epiglottis into the LM A cuff and its deflection (higher FOB grades) caused higher PIP especially in the smaller LM A. By comparing PIP and leak pressure, we know that PIP of the smaller LMAs was sometimes higher than the leak pressure. Because the leak through the LMA may increase at airway pressure $>25 \mathrm{CmH}_{2} \mathrm{O},{ }^{19}$ ventilation may be lost during inspiration.

In nine of 79 patients whose airways were maintained with a LMA throughout the surgery, the $\mathrm{P}_{\mathrm{ET}} \mathrm{CO}_{2}$ slowly increased. Although this sign occurs late, we could find no other earlier and reliable sign during the surgery. If surgery had continued longer, we may have had to abandon the LM A in more cases. Even if we could not hear an air leak with a stethoscope on the stomach, at the end of operation the abdomen appeared inflated or tympanic on percussion, so subclinical gastric insufflation might be a cause of the increased $\mathrm{P}_{E T} \mathrm{CO}_{2}$.

Compared with other reports without paralysis, 8,10 some problems related to insertion such as airway obstruction, coughing, laryngospasm, and difficulty with placement 8,10 were bypassed. Even though the complications during insertion were excluded, our overall complication rate was higher than in previous studies. ${ }^{8,10}$ Since this study group consisted of small children, the complication rate was high as was suggested by another study. ${ }^{8}$ Insertion of an LM A in paralyzed patients may affect the LMA position that cannot be detected by FOB. Thus it may have a high- 
er complication rate than when paralyzed after LMA insertion. ${ }^{8}$ Slowly increasing $\mathrm{P}_{\mathrm{ET}} \mathrm{CO}_{2}$ might be a particular complication of LMA insertion and maintaining PPV in paralyzed pediatric patients.

The pharyngeal, laryngeal and genioglossus muscles are relaxed under general anesthesia, ${ }^{20}$ and upper airway anatomy therefore changes when muscle relaxation is achieved. However, there has been no well-controlled study of LMA position in pediatric patients without paralysis. Furthermore, large variations in L M A position have been reported even in adults. Latorre and colleagues ${ }^{6}$ stated that the ideal position (FO B grade 1 ) was achieved in $70 \%$ of cases, but Fullekrug and colleagues ${ }^{5}$ reported that this figure was only $13 \%$ Thus it is difficult to say that, from the results of this study, whether mus cle relaxation has some definite effect on $L M A$ position.

From our clinical impression, higher PIP and more frequent occurrence of $\mathrm{P}_{E T} \mathrm{CO}_{2}$ increase with small $L M A s$, we think that the larger the LM A, the less the leakage was around the LM A. H owever, in our study, the $F_{L}$ of LMA 2 was not different from that of LMA 1 or 1.5 . In patients weighing $<10 \mathrm{~kg}$, we used the infantile breathing circuit and ventilator bellows, and neonatal pulmonary monitor, which has a lower dead space volume. As stated earlier, more ventilation was lost during inspiration through small LMAs. For the small LM As such as \# 1 and \# 1.5, $F_{L}$ was calculated to be relatively lower than it should be.

Because of the common occurrence of partial airway obstruction by the epiglottis while using the LM A in young children, the risk/ benefit ratio should be carefully evaluated before using an LM A with paralysis and PPV in this age group.

\section{References}

1 K umar CM. Laryngeal mask airway for inadequate reversal. (Letter) Anaesthesia 1990; 45: 792.

2 D evitt JH, Wenstone R, N oel A G, O'D onnell MP. The laryngeal mask airway and positive-pressure ventilation. Anesthesiology 1994; 80: 550-5.

3 Dich-N ielsen J O, $\mathrm{N}$ agel P. Flexible fibreoptic bronchoscopy via the laryngeal mask. Acta Anaesthesiol Scand 1993; 37: 17-9.

4 Graziotti PJ. Intermittent positive pressure ventilation through a laryngeal mask airway. Is a nasogastric tube useful? Anaesthesia 1992; 47: 1088-9.

5 Füllekrug B, Pothmann W, Werner C, Schulte am Esch J. The laryngeal mask airway: anesthetic gas leakage and fiberoptic control of positioning. J Clin Anesth 1993; 5: 357-63.

6 Latorre F, Eberle B, Weiler N, et al. Laryngeal mask airway position and the risk of gastric insufflation. Anesth Analg 1998; 86: 867-71.
7 Epstein R H , Ferouz F, J enkins M A. Airway sealing pressures of the laryngeal mask airway in pediatric patients. J Clin Anesth 1996; 8: 93-8.

8 Lopez-Gil M, Brimacombe J, A lvarez M. Safety and efficacy of the laryngeal mask airway. A prospective survey of 1400 children. Anaesthesia 1996; 51: 969-72.

9 R owbottom SJ, Simpson DL, Grubb D. The laryngeal mask in children. A fibreoptic assessment of positioning. Anaesthesia 1991; 46: 489-91.

10 Mason D G, Bingham R M. The laryngeal mask airway in children. Anaesthesia 1990; 45: 760-3.

11 Dubreuil M, Laffon M, Plaud B, Penon C, Ecoffey C. Complications and fiberoptic assessment of size 1 laryngeal mask airway. Anesth Analg 1993; 76: 527-9.

12 Mizushima A, Wardall GJ, Simpson DL. The laryngeal mask airway in infants. Anaesthesia 1992; 47: 849-51.

13 Brain A IJ. The Intravent $L$ aryngeal $M$ ask Instruction $M$ anual, 2nd ed. $H$ enley-on-Thames, England: Intravent I nternational, 1993.

14 I sserles SA, R ozenberg B. LM A - reduction of gas leak (L etter). Can J Anaesth 1995; 42: 449.

15 A sai T. D ifficulty in assessing the correct position of the laryngeal mask airway (Letter). Br J Anaesth 1994; 72: 366.

16 Wilson IG. The laryngeal mask airway in paediatric practice (Editorial). Br J Anaesth 1993; 70: 124-5.

17 Brain AIJ. The laryngeal mask - a new concept in airway management. Br J Anaesth 1983; 55: 801-5.

18 Brain AIJ. The development of the laryngeal mask-a brief history of the invention, early clinical studies and experimental work from which the laryngeal mask evolved. Eur J Anaesthesiol 1991; 4(Suppl): 5-17.

19 Ho-Tai LM, Devitt JH, N oel A G, O'D onnell MP. Gas leak and gastric insufflation during controlled ventila tion: face mask versus laryngeal mask airway. Can J Anaesth 1998; 45: 206-11.

20 Ochiai R, Guthrie R D, M otoyama EK. Effect of varying concentrations of halothane on the activity of the genioglossus, intercostals, and diaphragm in cats: an electromyographic study. A nesthesiology 1989; 70: 812-6. 